The college also needs to look more actively beyond the United Kingdom's borders. In developing countries health professionals at the front line need training. ${ }^{13}$ As part of its concern to narrow health differentials between rich and poor the college could promote policies to increase the inadequate sums spent by Western governments on development, particularly on the provision of primary care and education.

Pressure is growing to develop clear standards and guidelines for the management of common medical problems and to devise ways of monitoring the effectiveness of care. In these developments the respective roles of specialist and generalist will need clarifying. The Conference of Medical Royal Colleges and Faculties already meets regularly, and there is cross representation on several committees. The possibility of forming a unified "national college" was raised in 1845 and was revived in 1973 with the suggestion of an academy of medicine bringing together all specialties. ${ }^{14}$ Closer working relationships between specialists and generalists will certainly be necessary to make the best use of limited resources. This implies more joint educational and research initiatives. In 1950 Collings, in an influential report, portrayed a situation of widespread demoralisation and perfunctory care and stated that "the overall state of general practice is bad and still deteriorating." ${ }_{15}$ His article provided a stimulus for reform. A similar survey today would no doubt show a great deal of progress, but considerable improvements are still needed.

\section{ANDREW P HAINES}

Professor of Primary Health Care,

University College and Middlesex School of Medicine,

Whittington Hospital,

London N19 5NF

1 Hunt JH. Past attempts to found a "College of General Practitioners" one and a half centuries ago. In: Hunt JH, Pinsent RJFK, eds. A history of the Royal College of General Practitioners. In: Hunt JH, Pinsent RJFK, eds.

Lancaster. MTP Press, $1982: 1-5$.

Rose FM, Hunt JH. College of General Practice. BMf 1951;ii:908.

A college of general practice [editorial]. BMF 1951;ii:1076-7.

Royal College of General Practitioners Council. Summary statement on "Working for patients." London: RCGP, 1989

Royal College of General Practitioners. RCGP college development plan. A draft for circulation. London: RCGP, 1991

6 Royal College of General Practitioners Clinical and Research Division. Research in general practice. $\vec{\theta}$ A development plan for the 1990s. London: RCGP, 1991.

7 Williams WO. A survey of doctorates by thesis among general practitioners in the British Isles from 1973 to 1988 . Br F Gen Pract 1990;40:491-4.

8 Grav DP. Research in general practice: law of inverse opportunity. BMf 1991;302:1380-2.

9 Iliffe S, Haines A. Developments in British general practice. Fam Med 1989;21:169-70,175-6, O 229-30.

10 Delamothe T. Social inequalities in health. BMF 1991;303:1046-50. community. BMF 1988;296:173-6.

12 McBride M. Meeting on women doctors and the RCGP. RCGP Connections Issue 1991; No 33:5. 13 Frontline doctor [editorial]. Lancet 1991;338;155-6.

14 Sellors TH, Hill J, Richardson J, Himsworth H, Hunt J, Wright R, et al. An academy of medicine. BMF 1973;i:737.

15 Collings JS. General practice in England today. A reconnaissance. Lancet 1950; i:555-85.

\title{
Auditing necropsies
}

\section{Learning from surprises}

"Much can be learned about the living from the study of the dead," states the introduction to Autopsy and Audit, a report from a joint working party of the relevant royal colleges. ${ }^{1}$ But currently much of this opportunity is being lost. Now that each district health authority has a medical audit committee the time may have come to change this. The working party's report should help: it provides convincing evidence of the usefulness of necropsies in medical audit. The report reviews the many studies showing that about one in 10 cases coming to necropsy have pathological lesions that would have materially altered clinical management had they been identified before death.

The working party expressed concern about the fall in hospital necropsies, a trend that is occurring world wide. ${ }^{2}$ Necropsies are performed on about one in four people dying in England and Wales, ${ }^{3} 90 \%$ of these at the request of a coroner. Although the number of necropsies performed after obtaining a relative's permission has fallen considerably over the past 20 years, coroners' necropsies have fallen by only $6.6 \%$ in the past decade. ${ }^{4}$ For the purposes of clinical audit an adequate number of coroners' and non-coroners' necropsies need performing to a consistently high standard.

For the purposes of audit the joint working party recommends that whenever a necropsy is performed the relevant clinicians should receive a summary of significant lesions as soon as possible, usually within two days of the necropsy. A complete report should be dispatched within three weeks. A paper in this week's journal by Whitty and colleagues shows just how far below these standards some hospitals are falling (p 1244). ${ }^{5}$

According to the joint working party, all necropsies should be accompanied by histological examination of the tissues, although this is sometimes not possible for coroners' cases, where histological examination may not be considered neces- sary to establish the cause of death. The counterargument that histological examination is always required to give a precise cause of death and to define other contributing $\stackrel{\otimes}{\mathbb{D}}$ diseases - has not yet been tested. Histological examination of $\stackrel{\square}{\rightarrow}$ the hearts of children who died after cardiac surgery provideso을 a good example of this: myocardial necrosis is present in $40 \% \frac{3}{5}$ of cases but is visible to the naked eye in a much smaller proportion. ${ }^{6}$

The report suggests that the responsibility for obtaining permission for a necropsy should lie with the consultant in charge of the case and that members of the clinical team 3 . should be encouraged to attend either the actual necropsy or ai presentation of the important findings. In practice, both of these objectives will be difficult to achieve. Putting asideo constraints on time, there is the problem that non-pathol-n ogists find necropsies distasteful: in a survey of 41 under $-\mathrm{T}$ graduates 35 expressed "personal distaste" for necropsy.

Many undergraduates and junior doctors have never attended a necropsy and therefore have little insight into itsर्ज value in investigating disease. Perhaps the answer is to $\sigma$ provide good facilities for demonstration, both within and outside the mortuary. Hospital clinicopathological and mortality conferences are good forums for showing photographic + ? or video material from individual cases in aesthetically $\underset{T}{\mathbb{D}}$ acceptable surroundings in which the audit and scientific $\frac{\mathrm{O}}{\mathrm{D}}$ value of the necropsy can be fully appreciated. All medical undergraduate teaching courses should seek to provide these facilities.

If the scientific validity of the necropsy as a form of audit iso̊ to gain universal acceptance it is important that the necropsies themselves are properly performed and audited. As pointed out in a recent paper in this journal the necropsy, like any other scientific investigation, is not immune to error. ${ }^{8}$ This paper suggested that the sensitivity and specificity of clinical 
and postmortem diagnoses may be considerably distorted by either non-random selection of cases or by unrecognised errors in postmortem diagnosis.

Using assessors nominated by the Royal College of Pathologists, the national confidential enquiry into perioperative death $s^{9}$ is currently assessing the quality of necropsy reports, and preliminary reports suggest some cause for concern. This applies particularly to coroners' cases, for which reports may be brief, lacking any record of organ weights or histological examination. Given the high proportion of coroners' necropsies it is vital that for both purposes of audit and proper death certification they are performed "with the same thoroughness demanded by necropsies prompted by clinical requests." The Home Office is already introducing a quality assurance programme for forensic necropsies, and a similar scheme for other coroners' necropsies would be welcome. Another problem relating to coroners' necropsies is the unwillingness of some coroners to release their reports for the purposes of audit.

Autopsy and Audit is vague about the proportion of necropsies in hospital cases that would be acceptable for the purposes of audit and how such necropsies would be funded in a market driven NHS. It recommends that as well as necropsies performed for specific reasons-such as verifying the cause of death-a necropsy rate of at least $10 \%$ of other general hospital deaths should be the target. (Adopting an overall rate of $35 \%$ of all hospital deaths, as suggested in the early part of the report, may have been simpler.) The sampling system recommended will inevitably cause difficulties in defining whether a necropsy is being performed to verify the cause of death or as part of a random sample.

Regarding funding, the report hints that as necropsies provide an invaluable form of audit the costs might be met from medical audit budgets. Many would regard this as unrealistic as the total cost would exceed the entire funds available for medical audit. The Department of Health is currently examining the problem of funding and it seems likely to recommend that the cost of necropsies should be included within the general hospital overhead.

For necropsies to be effective as a form of audit the information that they yield needs to be properly used. District medical audit advisory committees should oversee this. For example, discrepancies between antemortem and postmortem diagnosis need to be "monitored and made available to consultants on an individual basis." Members of audit committees should study the report carefully and consider implementing its recommendations as soon as possible.

I LAUDER

Professor of Pathology,

Clinical Sciences Building,

Leicester Royal Infirmary,

Leicester LE2 7LX

1 Joint Working Party of the Royal College of Pathologists, the Royal College of Physicians of London, and the Royal College of Surgeons of England. The autopsy and audit. London: RCPath, RCP, RCS, 1991 .

2 Pathmanathan R, Chandrasekharan N. Declining post mortems: a cause for concern. Med $\mathcal{J}$ Malaysia 1985;40:267-70

3 Ashworth TG. Inadequacy of death certification: proposal for change. $\mathcal{F}$ Clin Pathol 1991;44:265-8.

4 Statistics of deaths reported to coroners: England and Wales 1990. Home Office Statistical Bulletin Issue 5, 1991

5 Whitty P, Parker C, Prieto-Ramos F, Al-Kharusi S. Communication of results of necropsies in North East Thames region. BMF 1991;303:1244-6.

6 Russell GA, Berry PJ. Post mortem audit in a paediatric cardiology unit. $f$ Clin Pathol 1989;42:912-8.

7 Benbow EW. Medical students' views on necropsies. $\mathcal{F}$ Clin Pathol 1990;43:969-76.

8 Saracci R. Is necropsy a valid monitor of clinical diagnosis performance? BMf 1991;303:898-900.

9 Campling EA, Devlin HB, Lunn JN. The report of national confidential enquiry into perioperative deaths 1989. London: Royal College of Surgeons, 1990.

\section{Risk factors in Alzheimer's disease}

\section{Not all solvable by molecular biology}

Clinical research on the causes of Alzheimer's disease is notoriously difficult. ${ }^{1}$ Most patients are old, diagnostic procedures are often incomplete, and coexistent disease often confounds ascertainment. Three factors are known to increase the risk of Alzheimer's disease: age, family history, and female sex. ${ }^{2}$ Down's syndrome has yielded the best clues about causation. The gene coding for the abnormal amyloid protein deposits in Alzheimer's disease has been firmly located on chromosome 21.

Genomic DNA and cDNA clones that encode amyloid precursor protein in Alzheimer's disease and Down's syndrome have been sequenced and in most instances are found to be identical with amyloid precursor protein in non-affected subjects. An uncertain proportion (probably a small minority) of patients with Alzheimer's disease of early onset carry a defect in the gene for amyloid precursor protein, the precise nature of which is known to vary between pedigrees. So far, three distinct mutations have been identified in eight pedigrees. ${ }^{3-5}$ Families with Alzheimer's disease of late onset and some familial early onset pedigrees do not show linkage between chromosome 21 markers $^{6}$ and the disease, and the extent to which studies on the molecular genetics of amyloid protein will prove pertinent to the aetiology in most cases of Alzheimer's disease remains unclear.

Genetic hypotheses do not readily accommodate observations such as those on monozygotic twins discordant for
Alzheimer's disease ${ }^{7}$ from which it has been clear for at least 30 years that unknown environmental factors are also implicated in the pathogenesis of the disease. ${ }^{8}$ That fact raises questions about the identity of putative neurotoxins, the duration of exposure, and the delay between exposure and the onset of symptoms. Already the pathogenesis of Alzheimer's disease is presumed to be complex; the environment can probably act at one or more stages in the development of the disease; and factors such as premorbid intelligence, education, and social integration may modify individual thresholds for symptomatic decompensation and survival time. ${ }^{910}$

In the face of such difficulties few researchers have set out on a systematic search for risk factors for Alzheimer's disease. The most practical approach has been to identify cases locally that meet strict criteria for the condition ${ }^{11}$ and to inquire from carers or relatives of these patients about exposure to hypothefical risk factors. Although comparisons with nonaffected controls are attempted, these are difficult to interpret, partly because of the likelihood that an appreciable proportion of non-affected subjects will themselves develop the disorder in time. Largely, however, recall bias by informants has been the major confounding effect. Too often, too much information is provided ("anything that could possibly help") or responses reflect only the informant's assumptions about the cause ("it's all because of the well water"). Nevertheless, a few studies have been competently 